\title{
SISTEMÁTICA E TAFONOMIA DOS CRUSTÁCEOS DECÁPODES DA ECOFÁCIES CAPANEMA DA FORMAÇÃO PIRABAS (MIOCENO INFERIOR), ESTADO DO PARÁ
}

\author{
VLADIMIR DE ARAÚJO TÁVORA ${ }^{1}$, NILSON MESQUITA ${ }^{2}$, SUSANE RABELO DE SOUZA ${ }^{1}$, ALESSANDRA SUZELY \\ MODA CACELA ${ }^{1} \&$ SHEILA GATINHO TEIXEIRA ${ }^{1}$
}

\begin{abstract}
SYSTEMATICAND TAPHONOMY OF DECAPOD CRUSTACEANS OF THE CAPANEMA ECOFACIES OF THE PIRABAS FORMATION (LOWER MIOCENE), PARA STATE, BRAZIL The systematic study of the decapod crustaceans of the Capanema ecofacies of the Pirabas formation (Lower Miocene), sampled in the B-17 deposit of the Cimentos do Brasil S/ACIBRASA, Capanema district, NE Pará State, has confirmed the occurence of the Calappa circularis Beurlen, Acanthocarpus. obscurtus (Rathbun), Portumus haitensis Rathbun, Callinectes reticulatus Rathbun and Scylla costata Rathbun species. Also recognized are Portunus atecuicitilis Vega et al., P. spinimanus Latreille, Necronectes tajinensis Vega et al. and Tetraxanthus rathbunae Chace, for the first time in Pirabas formation, and one undetermined species, Callinectes sp.1.

The taphonomic study reveals that the fossiliferous concentration was formed by the only event, and that your burial occured in sitt . The biostratinomic features suggest depositional environment with high energy during the burial event. The brachyura majority was buried after their death-normal position, although $45 \%$ represents specimens surprised by burial- escape position. The presence of the young and adults decapod suggest a event of high mortality, that implies in catastrophic event.
\end{abstract}

Keywords: Systematic, Taphonomy, Decapod crustaceans, Pirabas formation, Lower Miocene

RESUMO O estudo sistemático dos crustáceos decápodes da ecofácies Capanema da Formação Pirabas, nordeste do Estado do Pará, procedentes da jazida B-17 da Cimentos do Brasil S/A- CIBRASA, localizada no município de Capanema, confirmou a ocorrência das espécies Calappa circularis Beurlen, Acanthocarpus obscurtus (Rathbun), Portunus haitensis Rathbun, Callinectes reticulatus Rathbun e Scylla costata Rathbun. São apresentadas também, quatro espécies, ainda não assinaladas na Formação Pirabas, Portunus atecuicitilis Vega et al., P. spinimanus Latreille, Necronectes tajinensis Vega et al. e Tetraxanthus rathbunae Chace, além de uma espécie indeterminada, Callinectes sp.1.

O estudo tafonômico revelou que a concentração fossilífera se formou em um único evento, e que o seu soterramento ocorreu in situ. As feições bioestratinômicas sugerem que o ambiente deposicional apresentava alta energia durante o evento de soterramento, e que a maioria foi soterrada após a sua morte- posiç̃o normal, embora $45 \%$ deles represente indivíduos que foram surpreendidos pelo soterramento- posição de escape, caracterizando a geração da concentração fossilífera por ondas de tempestade. Um evento de mortandade em massa é sugerido através da presença de formas jovens e adultas na tafocenose, que implica em um evento catastrófico.

Palavras-chave: Sistemática, Tafonomia, Crustáceos decápodes, Formação Pirabas, Mioceno Inferior

INTRODUÇÃo Os crustáceos decápodes da ecofácies Capanema da Formação Pirabas foram classificados e descritos por Beurlen (1958) e Brito (1971). Depois disso foi apenas sugerido por Brito (1993) que este grupo sistemático como um todo fosse reestudado, a fim de que fosse possivel levantar mais dados sobre a carcinofauna da Formação Pirabas.

Desta forma, é aqui apresentado um estudo sistemático dos decápodes da ecofácies Capanema, procedentes de coletas recentes na jazida B-17 da Cimentos do Brasil S/A- CIBRASA, município de Capanema, nordeste do Estado do Pará (Fig 1.). Com $16 \mathrm{~m}$ de altura aproximadamente, a jazida representa uma porção da laguna do mar de Pirabas, e é litologicamente constituída por margas, calcarenitos e biocalcirruditos, onde neste último ocorrem os fósseis objeto desta pesquisa. Associados a estes constam corais, briozoários, moluscos (dominantemente), ostracodes e foraminíferos, além de nanofósseis calcários e peixes condrícteos.

Dentre o material examinado foram reconhecidos e caracterizados sete gêneros e dez espécies, sendo uma indeterminada. Para tanto, 20 exemplares foram analisados, visando a sua detalhada descrição sistemática. A excelente preservação do material, todos como restos inalterados, forneceu os subsídios necessários para a efetivação desta proposta.
FORMAÇ̃̃O PIRABAS A Formação Pirabas (Maury 1925) aflora descontinuamente nos estados do Pará, Maranhão e Piauí, representando um dos melhores documentos paleontológicos do Cenozóico marinho brasileiro. A unidade é eomiocênica, litilogicamente constituída por calcários de composição variável e representa um paleoambiente marinho de águas rasas e quentes com salinidade normal (Ferreira \& Cunha 1957, Petri 1957, Ferreira 1966, 1980, 1982, Ferreira \& Francisco 1988). O rico e variado conteúdo fossilífero inclui espécies dos principais filos animais, sugerindo a presença de três fácies ecológicas na Formação Pirabas: Castelo, Capanema e Baunilha Grande, associadas respectivamente a ambientes de mar aberto, laguna e mangue (Ferreira 1966, 1980, 1982, Ferreira \& Cassab 1985, Ferreira \& Francisco 1988). A idade eomiocênica, está baseada na presença de alguns fósseis guias, como o gastrópode Orthaulax pugnax (Heilprin) e algumas espécies de foraminíferos planctônicos do gênero Globigerinoides (Maury 1925, Ferreira 1967, Fernandes 1988, Fernandes \& Távora 1990, Távora \& Fernandes 1999).

As rochas sedimentares mio-pleistocênicas do Grupo Barreiras repousam discordantemente sobre a Formação Pirabas (Francisco et al. 1971), e segundo Ferreira \& Francisco (1988), não ocorre interdigitação entre estas unidades. Góes et al. (1990) reportaram 


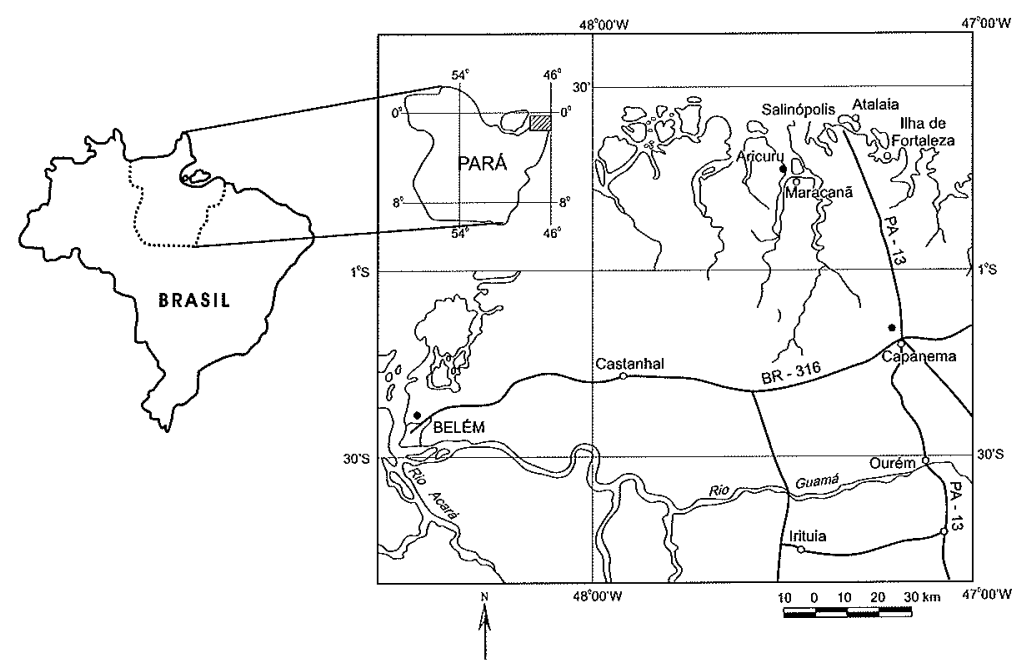

Figura 1 - Mapa de localização do afloramento de onde provém os decápodes estudados.

que o contato geológico entre a Formação Pirabas e o Grupo Barreiras é interdigitado e gradual, com base em estruturas sedimentares e palinomorfos. A disposição em superfície e subsuperfície dos sedimentitos Pirabas, sugere que a ecofácies Baunilha Grande, é descontínua e que está localizada acima da ecofácies Castelo e abaixo da Capanema (Ferreira 1980, 1982).

Considerando o conteúdo e análise paleontológica, Góes et al. (1990), assinalaram que a Formação Pirabas foi depositada em uma plataforma carbonática, assim como em lagunas e zonas intermarés com mangues. As análises litofaciológicas corroboram esta interpretação. Foram encontradas evidências de ondas de tempestade na plataforma continental, onde os subambientes de plataforma carbonática marinha rasa (ecofácies Castelo), laguna (ecofácies Capanema) e mangue (ecofácies Baunilha Grande) acham-se dispostos de forma interdigitada com sedimentação cíclica, sugerindo frequientes oscilações do nível do mar, e litoral intensamente recortado. Subsequiente a este evento deposicional, dominatemente transgressivo e oscilatório, predominou a sedimentação de uma outra sequiência, regressiva e siliciclástica (Grupo Barreiras), cujas estruturas sedimentares e conteúdo palinológico típico do Mesomioceno indicam certa contemporaneidade e gradação entre as sequiências Pirabas e Barreiras.

Segundo Costa et al. (1993) os sedimentos do Terciário Superior na região de Salinópolis, nordeste do Pará, são produtos de um ciclo transgressivo-regressivo, estando depositados em uma bacia assimétrica e alongada de direção NW-SE. O preenchimento desta bacia se processou pela instalação de depósitos marinhos carbonáticos de águas rasas e quentes (Formação Pirabas), os quais dão lugar gradativamente a depósitos regressivos de natureza siliciclástica (Grupo Barreiras), indicando forte soerguimento da borda da bacia e inibição da deposição de carbonatos em subambientes de planície de maré, estuário e plataforma interna. As estruturas que controlaram o desenvolvimento da Formação Pirabas e do Grupo Barreiras são falhas normais NW-SE e inclinadas para NE, e falhas transcorrentes NE-SW que funcionaram como zonas de transferência. Essa evolução é entendida como decorrente do último episódio de manifestação extensional na margem equatorial brasileira, relacionado ao evento de separação América do Sul- África.

A CARCINOFAUNA DA ECOFÁCIES CAPANEMA A carcinofauna da ecofácies Capanema da Formação Pirabas tem sido objeto de poucos estudos, pontificados por dois pesquisadores, Beurlen (1958) e Brito (1971). Anos mais tarde, em 1993, Brito realizou uma análise sobre o estado da arte do conhecimento da carcinofauna nos sedimentos miocênicos do nordeste do Estado do Pará.

Beurlen (1958) realizou a caracterização sistemática dos crustáceos decápodes pertencentes aos grupos Oxystomata, Oxyrhyncha, Cancriformia e Brachyrhyncha na Formação Pirabas, procedentes de afloramentos localizados nas zonas fisiográficas do Salgado e Bragantina, nordeste do Estado do Pará. Foram registradas sete novas espécies, cinco anteriormente definidas por Rathbun em estratos da região caribeana, e duas indeterminadas, além de trazer incertae sedis da Família Xanthidae.

Neste trabalho, o autor considerou que as faunas de braquiúres tropicais terciários da América Central e do Pará representam zoogeograficamente uma unidade bem típica. A predominância dos calapídeos e raridade dos xantídeos reforçam esta teoria. Supõe-se que esta fauna presente na Formação Pirabas seja precursora das espécies atuais da costa brasileira. Ainda segundo esse autor, a composição da fauna, o seu modo de conservação e o tipo de sedimento em que estes braquiúres estão inclusos, permitem caracterizar o seu ambiente de vida como o marinho de águas rasas e bem movimentadas. Devido a maior identidade destes crustáceos decápodes com os registrados no Oligoceno, além da ausência do gênero Necrenectes, tipicamente miocênico, registrado no Panamá e Estados Unidos, Beurlen considerou que seria mais correto datar a Formação Pirabas como neo-oligocênica.

Brito (1971) ampliou os conhecimentos sobre os crustáceos decápodes da Formação Pirabas. Assinalou pela primeira vez o gênero Panopeus e detalhou a caracterização morfológica de quatro espécies reconhecidas por Beurlen. Além disso propôs duas novas espécies atribuídas ao gênero Callinectes, $C$. pirabensis e C. ferreirai, com ocorrências nas ecofácies Capa-nema e Baunilha Grande, respectivamente.

Brito (1993) considerou que a carcinofauna da Formação Pirabas apresenta-se com aspecto tipicamente neogênico, e muitos dos elementos estão presentes nas biotas atuais. Tendo em vista que a maior parte dos táxons reconhecidos na referida Formação estão representados por fragmentos e/ou poucos exemplares, o autor admitiu que para melhor comparação destes com espécies recentes é necessário realizar novas coletas. Ainda neste trabalho, Brito reuniu os dados paleoambientais, geográficos e geocrono- 
lógicos referentes à carcinofauna da Formação Pirabas existentes na literatura. Com base nestas informações, o autor reconheceu que a maioria dos táxons fósseis está presente nas carcinofaunas atuais da região caribeana e costa brasileira.

SISTEMÁTICA PALEONTOLÓGICA Utiliza-se no presente estudo as classificações sistemáticas adotadas por Brooks et al. (1969) e Beurlen (1958), além de outras bibliografias complementares específicas, tais como Vega et al. (1999). A nomenclatura morfológica e os termos aplicados nas descrições sistemáticas seguem a proposta de Brooks et al. (1969) e Melo (1996). Os exemplares estão depositados na coleção paleontológica do Museunde Geociências da Universidade Federal do Pará.

Filo ARTHROPODA Siebold \& Stannius, 1845

Subfilo MANDIBULATA Clairville, 1798

Classe CRUSTACEA Pennant, 1777

Ordem DECAPODA Latreille, 1803

Infraordem BRACHYURA Latreille, 1803

Seção OXYSTOMATA Milne Edwards, 1834

Superfamília CALLAPOIDEA de Haan, 1833

Tamília CALLAPIDAE de IIaan, 1833

Subfamília CALLAPINAE de Haan, 1833

Gênero Calappa Weber, 1795

Calappa circularis Beurlen, 1958

Descrição: Carapaça subcircular (Fig. 2), com margem posterior curta e subretilínea, encurvada em direção às margens laterais. Superfície da carapaça abaulada longitudinalmente, com dois sulcos longitudinais rasos, que limitam a zona cardiogástrica. Zona mediana ornamentada por tubérculos que marcam as regiões cardial e mesogástrica, e pequenas pústulas irregularmente distribuídas nas regiões protogástricas.

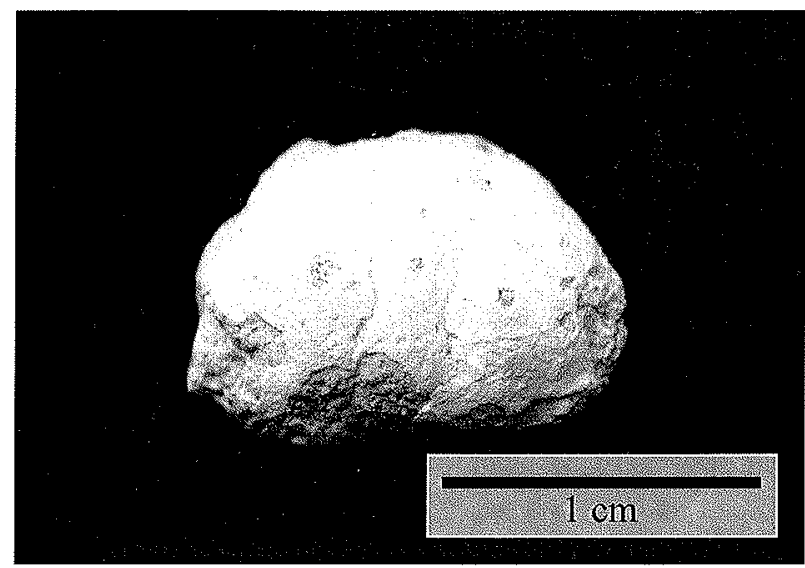

Figura 2 - Calappa circularis Beurlen, 1958 (MG-450I-I)

Ocorrência: ecofácies Castelo e Capanema da Formação Pirabas. Material; um espécimen com região anterior fragmentada (MG4501-I).

Genus Acanthocarpus Stimpson, 1871

Acanthocarpus obscurus (Rathbun, 1918)

Descrição: Carapaça de contorno subcircular (Fig. 3). Margem posterior curta, moderadamente encurvada. Linha de maior extensão transversal localizada na metade do comprimento da carapaça, marcando o limite das margens postero e anterolateral. Super-

Revista Brasileira de Geociências, Volume 32, 2002 fície abaulada no sentido de maior comprimento e mais suave no sentido de menor comprimento. Regiões cardíaca e gástrica formando uma zona média longitudinal, limitada por dois sulcos longitudinais bem pronunciados nas regiões cardíaca e mesogástrica. Ornamentação consistindo em tubérculos bem desenvolvidos e bem espaçados, localizados nas regiões cardiaca e mesogástrica, e constituindo uma fileira longitudinal nas zonas laterais.

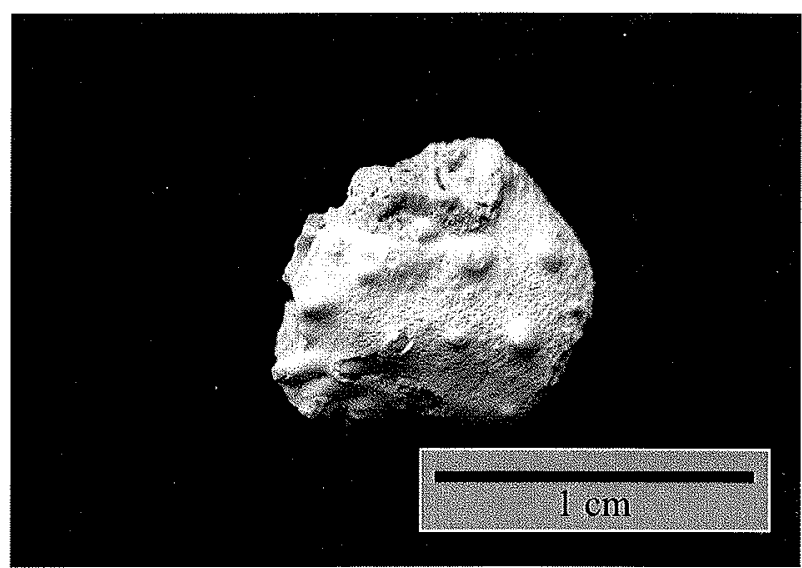

Figura 3 - Acanthocarpus obscurus (Rathbun, 1918) (MG4502-I)

Ocorrência: Oligoceno do Panamá e ecofácies Capanema da Formação Pirabas.

Material: dois espécimens fragmentados (MG-4502-I e 4503-I).

Seção BRACHYRHYNCHA Borraidale, 1907

Superfamília PORTUNOIDEA Rafinesque, 1815

Família PORTUNIDAE Rafinesque, 1815

Subfamília PORTUNINAE Rafinesque, 1815

Gênero Portunus Weber, 1995

Portunus atecuicitilis Vega et al., 1999

Descricão: Carapaça típica do gênero (Fig. 4), com tamanho médio a grande e largura duas vezes o seu comprimento, arqueada transversal e longitudinalmente. Margens frontal e antero-lateral formando um arco liso. Frente moderadamente larga. Regiões branquiais entumescidas, com uma forte costela na frente do arco car-

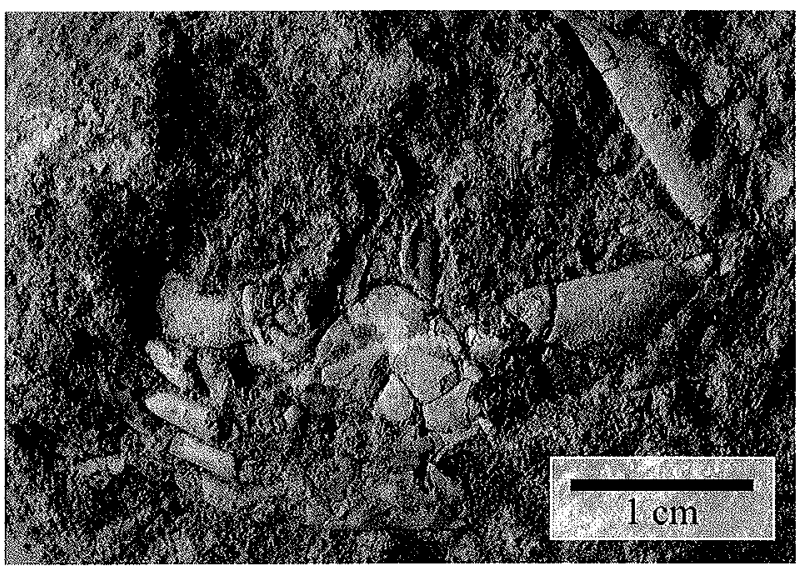

Figura 4 - Portunus atecuicitilis Vega et al., 1999 (MG-4506-I) 
díaco. Uma outra costela ocorre transversalmente, atingindo as regiões proto e mesogástrica. Superfície da carapaça ornamentada com grânulos espaçados, exceto na região frontal, que é lisa ou finamente pustulosa. Esternitos toráxicos típicos da família, não fusionados, com exceção dos elementos 1- 3. A metade anterior do esternito 4 é marcadamente inferior do que na metade posterior. Esterno largo tomando cerca de $50 \%$ da carapaça. Telso e pelo menos dois somitos abdominais formam um triângulo isósceles, onde sua parte mais larga corresponde aos somitos 3-5 fusionados. Somitos abdominais proximais reduzidos, subverticais. Quelípodes alongados e muito maiores do que as patas ambulatórias. Mero triangular em seção transversal, com pelo menos três espinhos na margem interna. Carpo com espinho proemimente na articulação interna com o mero e proeminências nodosas nas articulações com o própode. Própode finamente quilhado e alongado. Pereiópodes representados somente por elementos proximais.

Ocorrência: Formação Tuxpan, Mioceno do México e ecofácies Capanema da Formação Pirabas.

Material: cinco espécimens inteiros e articulados, sendo quatro machos (MG-4504-I, MG-4505-I, MG-4506-I e MG-4507-I) e uma fềmea (MG-4508-I).

Portunus haitensis Rathbun, 1924

Descrição: Carapaça de tamanho pequeno a médio (Fig. 5), mostrando a região ventral onde se observam o esterno e o abdômen. Esterno subcircular, mais largo do que longo, com cinco esternitos alongados na direção das coxas, estreitos na base e mais largos na metade da parte superior, a partir de onde começam a adquirir forma arredondada. Separam-se entre si e das coxas por sulcos bem marcados. O abdômen, estreito e comprido, tem forma de um triângulo isósceles, dividindo-se em dois somitos abdominais também separados por sulcos retos e profundos bem definidos. Os somitos correspondem aos esternitos 1-4. O telso, pequeno, tem forma de um triângulo equilátero, com vértice superior sobre o esternito 5. Na base do abdômen ocorrem três carenas bem marcadas, paralelas, longitudinais, assim como pequenos grânulos.

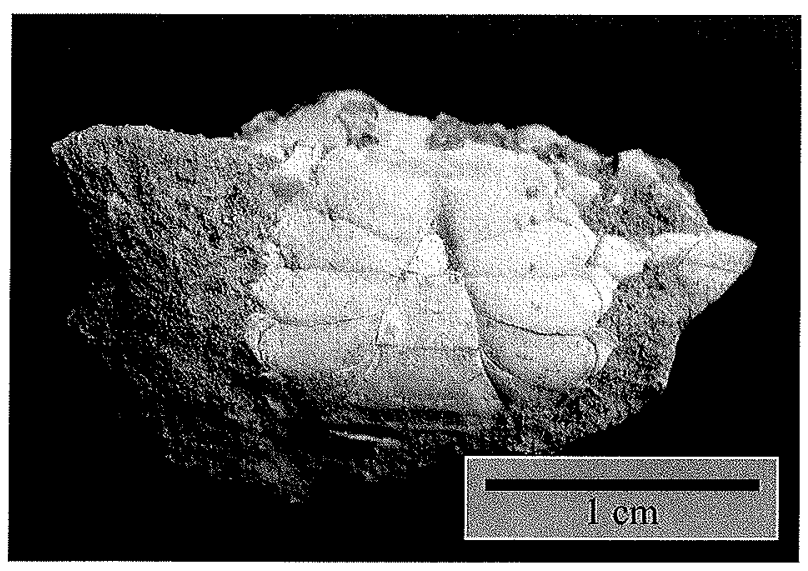

Figura 5- Portunus haitensis Rathbun, 1924 (MG-4509-I)

Ocorrência: Mioceno do Haiti e ecofácies Capanema da Formação Pirabas.

Material: três abdômens completos de indivíduos machos adultos (MG-4509-I, MG-4510-I e MG-4511-I).
Portunus spinimanus Latreille, 1819

Descrição: Carapaça pubescente (Fig. 6), exceto nas porções mais elevadas, e mais larga do que longa. Apresenta quatro saliências, gástrica, cardíaca e as duas branquiais. Além destas, ocorre uma outra, que começa atrás da órbita, continua ao longo da base dos dentes anterolateriais 3- 6 e é curva. Dentes frontais como espinhos com sinus mediano em forma de " $U$ ". Dentes anterolaterias 2- 8 rasos e pontiagudos. Quelípodes fortes, com quatro ou cinco fortes dentes na margem interna do mero, e um pequeno dente na externa. Palma com espinho no quarto distal. Margem externa ao abdômen sinuosa.

Ocorrência: como atual no Atlântico ocidental, golfo do México, Antilhas, Venezuelas, Guianas e Brasil; e como fóssil na ecofácies Capanema da Formação Pirabas.

Material: um espécimen macho pouco fragmentado e articulado (MG-4512-I).

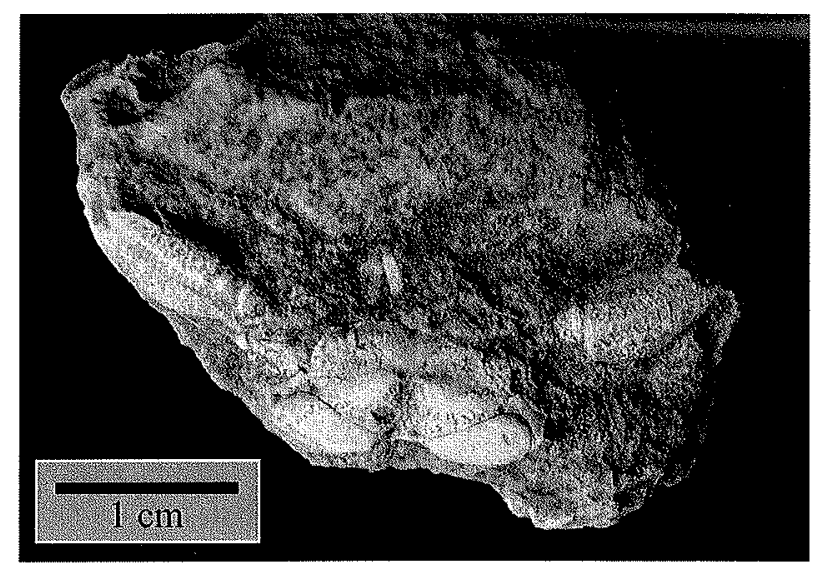

Figura 6 - Portunus spinimanus Latreille, 1819 (MG-4512-1)

Gênero Callinectes Stimpson, 1860

Callinectes reticulatus Rathbun, 1918

Descrição: Própode de tamanho médio (Fig. 7) com fragmentos do dedo fixo e a articulação do dedo móvel, com ambas as margens divergindo para a frente. A região exterior é ligeiramente convexa e ornamentada por três carenas longitudinais bem definidas, sendo que a superior é reta e paralela à carena da região inferior. A carena mediana é bem proeminente, e a região localizada entre elas é côncava. O lado externo separa-se do interno por uma região retangular subplana. $O$ lado interno também apresenta três carenas longitudinais retilíneas e menos proeminentes do que as do lado externo. A carena mediana termina na região entre o dedo fixo e a articulação do dedo móvel por um espeinho. Toda a superfície do própodo é rugosa.

Ocorrência: Oligoceno do Alabama (EEUU) e ecofácies Capanema da Formação Pirabas.

Material: um própode de um indivíduo macho adulto (MG-4513-I).

\section{Callinectes sp. 1}

Descrição: Carapaça de tamanho médio (Fig. 8), mais longa do que larga, de contorno semicircular, bastante convexa. Margens anterolaterais marcadas por espinhos com pontas arredondadas, sendo que o lateral é maior e pontiagudo, e a partir dele os demais decrescem de tamanho suavemente. As regiões cardíaca e gástrica são limitadas por dois sulcos transversais que as separam em uma zona média e desaparecem nas regiões frontal e intestinal. As regiões hepática, mesogástrica, epibranquial e anterolateral são ornamentadas por tubérculos de vários tamanhos distribuídos irre- 


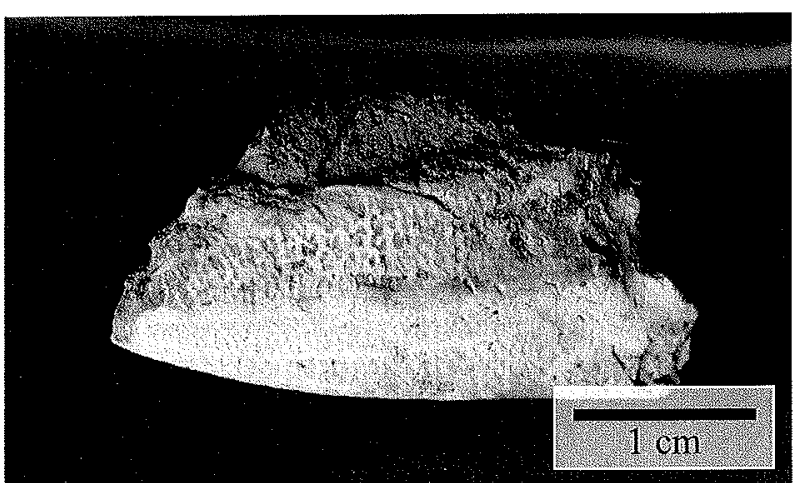

Figura 7. Callinectes reticulatus Rathbun, 1918 (MG-4513-I)

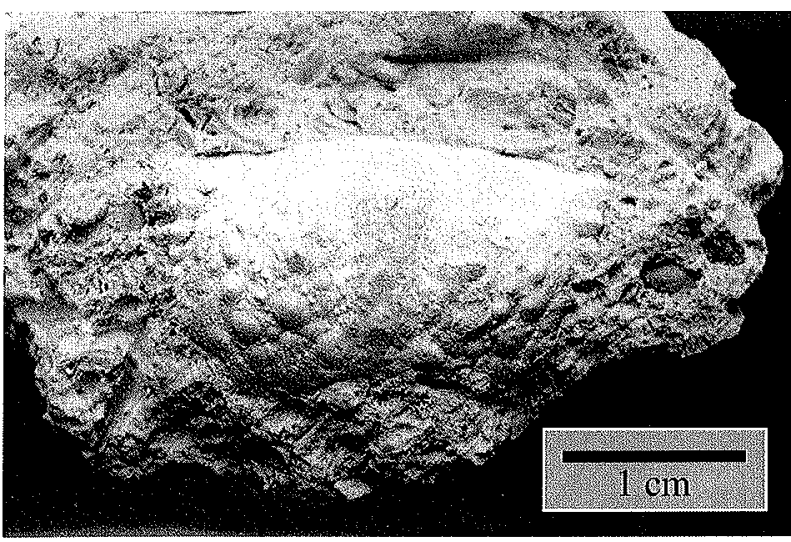

Figura 8-Callinectes sp.1 (MG-4515-I)

gularmente.

Ocorrência: ecofácies Capanema da Formação Pirabas.

Material: dois exemplares, preservados apenas o tórax, sendo um jovem (MG-4514-I) e outro adulto (MG-4515-I).

Gênero Necronectes Milne Edwards, 1881

Necronectes tajinensis Vega et al., 1999

Descrição: Carapaça mais larga do que longa (Fig. 9), com largura aproximadamente 1,5X o máximo comprimento. Superfície dorsal finamente granulada, pouco convexa transversalmente. Margem frontal com quatro espinhos triangulares com ápices arredondados, separados entre si por sulcos profundos em forma de " $U$ ". espinhos frontolaterais mais robustos, e mesial um tanto mais projetado. Margem anterolateral subigual à lateral, convexo, dotado de oito espinhos triangulares agudos separados por sulcos estreitos. Primeiro espinho agudo, com base estreita e os demais com base alargada. Sulco cervical bem definido ao longo das margens lateral e posterior da região mesogástrica. Região gástrica pouco inflada e regiões proto-gástricas definidas por duas elevações amplas e arredondadas, separadas anteriormente por uma estreita depressão axial. Região cardíaca levemente inflada, definida por sulcos pouco profundos. Esternitos toráxicos estreitos, fusionados. Processo esternal lateral bem definido, côncavo e recurvado na altura do quinto esternito. Abdômen não preservado. Quelípode direito reto, finamente granulado. Coxa, base e ísquio visíveis ventralmente, articulados. Coxa subquadrada, base pequena e triangular,

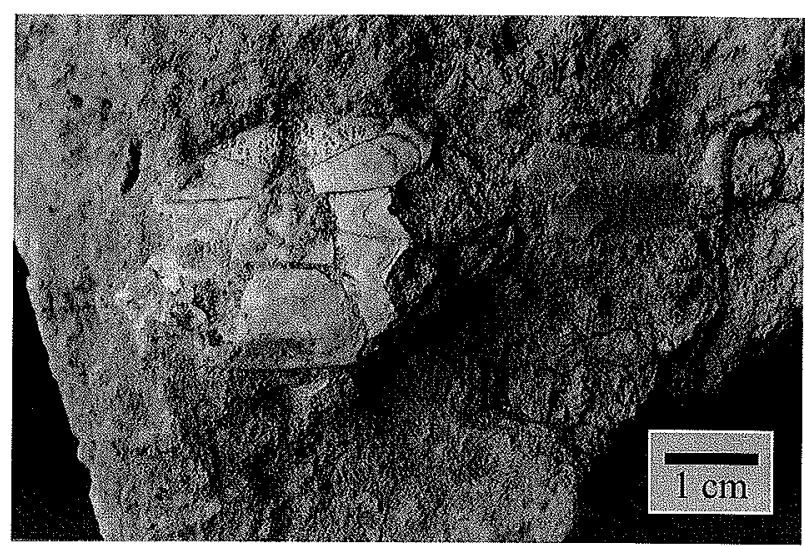

Figura 9- Necronectes tajinensis Vega et al., 1999 (MG-4516-I)

ísquio com margem anterior recurvada e com forma triangular. Mero do quelípode com articulação carpal forte e bem projetada. Carpo robusto, triangular, com margem anterior arredondada $\mathrm{e}$ superfície dorsal finamente granulada.

Ocorrência: Formação Tuxpan, Mioceno do México e ecofácies Capanema da Formação Pirabas.

Material: um especimen pouco fragmentado e ainda articulado (MG-4516-I).

Gênero Scylla de Haan, 1833

Scylla costata Rathbun, 1919

Descrição: Própode incompleto (Fig. 10), de tamanho médio a grande, sem os dedos, com margens inferior e superior subparalelas divergentes para a frente. O própode tem contorno subretangular convexo, com os lados intero e externo separados por uma região abaulada, dando aspecto entumescido à palma. No lado exterior ocorrem duas carenas longitudinais e paralelas à margem superior, tendo entre elas uma superfície levemente côncava. Duas carenas pouco pronunciadas separam as regiões exterior e interior. No lado interior também observam-se três carenas,

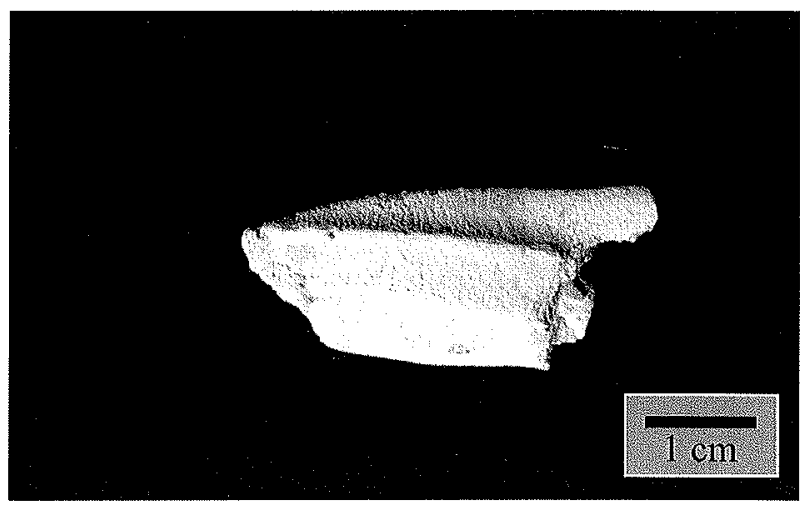

Figura 10 - Scylla costata Rathbun, 1919 (MG-4517-I)

separadas por uma superfície côncava, sendo que da base até o meio da palma a carena é bem pronunciada e a região bastante côncava. A partir deste ponto torna-se quase plana. O própode é ornamentado por rugosidades.

Ocorrencia: Mioceno do Haiti e ecofácies Castelo e Capanema da Formação Pirabas.

Material: dois própodes de indivíduos machos adultos (MG-4517- 


\section{I e MG-4518-ISuperfamília XANTHOIDEA Dana, 185I}

Família XANTHIDAE Dana, 1851

Gênero Tetraxanthus Chace, 1939

Tetraxanthus rathbunae Chace, 1939

Descrição: Carapaça subquadrada (Fig. 11), finamente granulada, bastante convexa anteroposteriormente. Regiões gástrica e hepática pouco evidentes. Fronte avançada, quase reta. Órbitas grandes, correspondendo a metade do comprimento da fronte, ângulo orbital esterno pequeno e subtriangular. Margem anterolateral com três lóbulos ou dentes atrás do orbital, onde o segundo é bastante largo e raso, e o terceiro obtuso, com margem posterior sublongitudinal. Quelípodes longos, fortes, lisos e desiguais. Patas ambulatórias não preservadas.

Ocorrência: como atual no Atlântico ocidental, golfo do México, Antilhas e Brasil; e como fóssil na ecofácies Capanema da Formação Pirabas.

Material: dois espécimens articulados e parcialmente fragmentados (MG-45 I9-I e MG-4520-I).

CONSIDERAÇÕFS PALEOAMBIENTAIS, ZOOGEOGRÁ-FI-

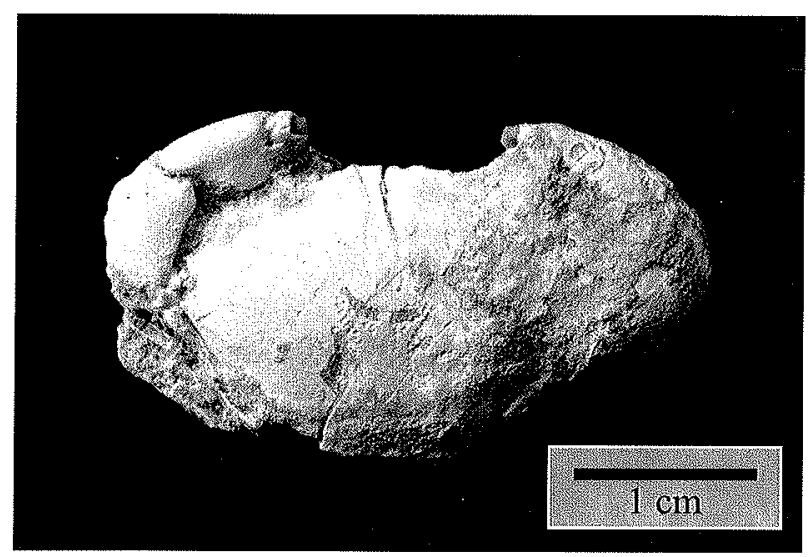

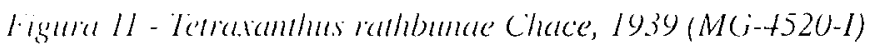

CAS E BIOCRONOLÓGICAS SOBRE A CARCINOFAUNA

ESTUDADA O estudo sistemático da carcinofauna da ecofácies Capanema da Formação Pirabas confirmou a ocorrência de Calappa circularis Beurlen, Acanthocarpus obscurus (Rathbun), Portunus haitensis Rathbun, Callinectes reticulatus Rathbun e Scylla costata Rathbun, assinalados por Beurlen (1958) e Brito (1971), sendo que o primeiro táxon fora reconhecido apenas na ecofácies Castelo.

Além disso, foram reconhecidas quatro espécies ainda não assinaladas na Formação Pirabas. Portunus atecuicitilis Vega et al. e Necronectes tajinensis Vega et al. ocorrem nos estratos miocênicos da Formação Tuxpan, México. Segundo Beurlen (1958), o gênero Necronectes inclusive, é típico das faunas miocênicas de braquiúres das regiões mediterrânea e atlânticas, estando também representado no Mioceno do Panamá e Maryland (EEUU), o que ratifica a idade miocênica para a Formação Pirabas. Portunus spinimanus Latreille e Tetraxanthus rathbunae Chace são espécies encontradas atualmente na costa brasileira. Estes quatro registros inéditos ampliam o conhecimento sobre a carcinofauna da Formação Pirabas, composta por táxons muito comuns nas faunas de braquiúres desde o início do Terciário. Estes dados ainda corroboram Brito (1993), que conferiu à carcinofauna pirabense, um aspecto moderno, muito próximo da fauna de crustáceos decápo- des viventes atualmente na costa brasileira.

É possível ainda que a espécie indeterminada, Callinectes sp.I corresponda igualmente a um táxon inédito na Formação Pirabas, haja vista que suas feições morfológicas diferem grandemente das apresentadas por outras espécies do gênero definidas até o momento.

As faunas de braquiúres terciários da América Central e do Pará representam uma unidade zoogeográfica bem definida, constituída basicamente por calapídeos, portunídeos, xantídeos e famílias afins, assim associadas por condições climáticas uniformes, tropicais (Beurlen 1958).

Do ponto de vista paleoambiental a carcinofauna é eurihalina, e é típica de ambiente marinho de águas rasas e agitadas, de clima tropical (Beurlen 1958, Vega et al. 1999).

TAFONOMIA DE CRUSTÁCEOS DECÁPODES A tafonomia de crustáceos decápodes é ainda pouco conhecida e o registro geológico destes organismos é esparso e fragmentário.

Segundo Bishop (1986) fatores biológicos como densidade e mobilidade da população, calcificação diferencial entre os diversos grupos e as ecdises influem grandemente no grau de preservação desses animais. Esse autor realizou estudo detalhado quanto à tafonomia de crustáceos decápodes discutindo modelos para as feições bioestratinômicas e diagenéticas:

Feições bioestratinômicas POSIÇÕES GERAIS DE SOTERRAMENTO (a) posição de escape (ou posição traumática)- os indivíduos são soterrados vivos, cuja evidência seria a posição dos apêndices e garras, dispostos sobre a carapaça, e abertos no sedimento circundante; (b) posição normal- os indivíduos quando soterrados já estão mortos. Apresentam os apêndices alinhados com as margens laterais, e as pinças estão fechadas e dobradas para a frente; $\mathrm{e}$ (c) posição de molde aberto- quando tem-se apenas os vestígios dos decápodes em forma de moldes, que representam carapaças caídas para a frente e rotacionadas.

A diferenciação entre cada uma destas categorias é bem complexa, pois faltam evidências para definir se uma dada posição é verdadeira ou circunstancial.

Além disso, a diagênese, relacionada com as condições de soterramento, taxa e profundidade de sedimentação, e a presença de organismos necrófagos ou

bioturbadores, influenciam grandemente no resultado final, o fóssil em análise. Uma outra limitação do modelo é a impossibilidade de usá-lo em formas sem esqueleto mineralizado.

CLASSES DE CONDIÇÕES DE SOTERRAMENTO (a) soterramento imediato- sugerido a partir do reconhecimento da posição de escape; (b)soterramento demorado- os restos apresentam-se fragmentados. Inicialmente o indivíduo dilata-se, devido aos gases produzidos por putrefação. Essa dilatação causa a quebra da carcaça, separando inicialmente abdômen e esterno com os apêndices. A desintegração das partes moles e a dinâmica ambiental transformam a carcaça em unidades desassociadas: carapaça, esterno, abdômen e apêndices; e (c) exumação- quando os restos já soterrados são novamente expostos à dinâmica ambiental. No caso dos restos estarem soterrados em sedimentos inconsolidados, são destruídos rapidamente por abrasão.

Feições diagenéticas TIPOS DE PRESERVAÇÃO DE CRUSTÁCEOS DECÁPODES (i) restos levemente alterados, preservados em matriz clástica fina com poucas modificações- adição de 
cimento calcítico; (ii) restos preservados como alóque-mes em rochas carbonáticas; (iii) restos preservados em concreções calcíticas suportadas por clásticos finos; (iv) restos presevados em nódulos apatíticos; (v) restos preservados em concreções calcíticas; (vi) restos preservados em concreções apatíticas; (vii) restos preservados em concreções hematíticas; e (viii) impressões em calcários litográficos.

Bishop (1986) ainda observou que além dos fatores biológicos e geológicos que dificultam a preservação de crustáceos decápodes, e seu consequiente registro geológico, também a dispersão dos fósseis até agora catalogados em coleções paleontológicas, assim como a divulgação da existência destes em acervos, representam um impedimento para o avanço do conhecimento sobre o grupo como um todo, sob o ponto de vista sistemático, tafonômico e filogenético.

Os decápodes depositados em museus, serviços geológicos ou universidades foram em sua maioria doados por geólogos, paleontólogos, ou mesmo leigos, que os obtiveram em trabalhos de campo direcionado a outros objetivos, ou mesmo durante abertura de estradas, poços ou edificações. Desta forma, não foram coletados os dados que norteiam a interpretação tafonômica, e por vczes falta até a procedência exata do exemplar ou exemplares.

Pelo exposto, observa-se que a falta de uma coleta adequada dos fósseis de crustáceos decápodes fósseis, configura-se em um elemento filtrador de informações para o avanço sobre o conhecimento deste grupo de artrópodos na ciência paleontológica.

\section{TAFONOMIA DOS CRUSTÁCEOS DECÁPODES DA} ECOFÁCIES CAPANEMA Os crustáceos decápodes da ecofácies Capanema da Formação Pirabas estão preservados em biocalcirruditos, sob a forma de restos inalterados, com cerca de $45 \%$ de espécimens articulados na amostragem. De uma maneira geral apresentam bom estado de preservação, inclusive tridimensionalmente.

Na maior parte do material amostrado (77\%) os espécimens estão pouco fragmentados. O restante parece ter sofrido algum tipo de ação erosiva ou antrópica.

Variações no tamanho dos braquiúres e em suas particularidades de formas jovens e adultas atestam que ambos os estágios ontogenéticos estão presentes nesta tafocenose, o que sugere eventos de mortandade em massa.

Com base nas feições preservadas foi possivel tecer algumas considerações tafonômicas. Cabe ressaltar que exame petrográfico tanto dos fósseis quanto das rochas que os contém forneceria mais dados para a interpretação tafonômica, pois através do mesmo se teriam feições diagenéticas. Entretanto, o dimensionamento desta pesquisa é limitado às feições macroscópicas como elementos para se traçar preliminarmente a trama tafonômica dos crustáceos decápodes estudados.

As feições macroscópicas.empregadas na descrição da concentração fossilífera, as quais são importantes também na identificação dos diferentes processos físico-químicos e biológicos responsáveis pela sua origem. Tais feições podem ser agrupadas em diversas categorias. Neste trabalho são apresentadas as feições sedimentológicas, estratigráficas e bioestratinômicas.

Feições sedimentológicas O grau de empacotamento observado no biocalcirrudito e sua relação com os decápodes é do tipo densamente empacotado (Kidwell \& Holland 1991), ou seja, a concentração é suportada por bioclastos, com as partículas pequenas ou cimento interstícial. A concentração fossilífera é dominada por bioclastos em várias classes de tamanho, podendo ser considerada como baixo grau de seleção. Isto reflete baixo grau de retrabalhamento e transporte assim como baixa taxa de sedimentação, podendo caracterizar um aumento brusco na disponibilidade de bioclastos.

Feições estratigráficas A concentração fossilífera ocorre em camada, considerada como uma feição tridimensional, com reconhecida estrutura interna simples, por não exibir variação lateral da concentração fossilífera. Os bioclastos encontram-se concordantes com a matriz que os envolve, ou seja, ocorrem horizontalmente em relação ao substrato (Kidwell et al. 1986).

Estas feições sedimentológicas e estratigráficas podem indicar que a concentração fossilífera se formou em um único evento, e que o seu soterramento ocorreu in situ.

Feições bioestratinômicas GRAU DE ARTICULAÇÃO Dos 20 exemplares estudados, $45 \%$ apresentam-se como formas preservadas com patas ambulatórias e quelípodes ainda articulados com o tórax e esterno, e um exemplar onde tórax e esterno ainda estão articulados, embora sem as patas ambulatórias. Além disso alguns quelípodes, própodes, tóraxes ou esternos isolados também são freqüientes.

GRAU DE FRAGMENTAÇÃO Os espécimens desarticulados apresentam-se domimantemente inteiros (77\%). Estas porcentagens de graus de articulaçõo e fragmentação indicam baixa energia do ambiente deposicional.

POSIÇÕES GERAIS E CONDIÇÕES DE SOTERRAMENTO (MODELO DE BISHOP 1986) Da tafocenose estudada, $45 \%$ apresentam-se em posição de escape, e o restante em posição normal de soterramento. A posição de escape de alguns indivíduos representa que os mesmos foram surpreendidos pelo soterramento (Fig. 4). A posição normal de soterramento dos demais indica que eles foram soterrados somente após a sua morte (Figs. 5 e 7). Cabe ressaltar que na maioria dos exemplares da tafocenose os indivíduos não apresentam qualquer evidência de quebra ou compressão.

Finalmente, também foi possível reconhecer feições antró-picas em alguns indivíduos, oriundas do momento da coleta ou desmanche da seqüência sedimentar por ocasião da extração do calcário para beneficiamento.

IMPLICAÇÕES PALEOAMBIENTAIS Todas as feições preservadas identificadas nos crustáceos decápodes e suas rochas encaixantes permitem supor que a concentração fossilífera em questão foi gerada por ondas de tempestade. A boa qualidade da preservação assim como o não reconhecimento de evidências de abrasão, bioerosão e incrustação nos espécimens, sustentam essa assertiva. Entretanto, a considerável porcentagem de formas articuladas e tridimensionalmente preservadas, que indica exumação, reorientação e rápido soterramento de animais ainda vivos, caracterizam indubitavelmente a geração da concentração fossilifera por ondas de tempestade (Fursich e Oschmann 1993 , Simões 1996).

As condições de formação da concentração fossilífera coincidem com os dados apresentados por Góes et al. (1990), que registraram ocorrência de ondas de tempestade na plataforma continental do mar de Pirabas. Assim, pode-se sugerir que tempestades estejam relacionadas com um evento de mortandade em mas- 
sa na paleolaguna Capanema, suportada pela identificação de vários estágios ontogenéticos de braquiúres.

MODELO DE TAFOFÁCIES De acordo com a análise tafonômica apresentada, a proposição de um modelo para os crustáceos decápodes da ecofácies Capanema da Formação Pirabas, pode caracterizá-los em uma tafofácies (Fig. 12) aqui denominada por Tafofácies de braquiúres da ecofácies Capanema.

\section{Agradecimentos Aos revisores da RBG pelas sugestões ao manuscrito.}

\section{Figura 12 - Tafofácies de braquiúres da ecofácies Capanema}

\begin{tabular}{|c|c|}
\hline FEICYOES PRESERVACIONAIS & 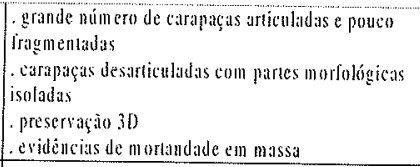 \\
\hline AMB LENTE DEPOSICIONAL & L:iguatar \\
\hline FOSSEIS ASSOCHDOS & 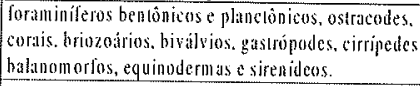 \\
\hline SEDIMENTO ASSOCIADO & biocialcirrudito \\
\hline UNIDADF LITOFSTRATIGRAFICA & Formatyò̀ Pirabals \\
\hline IDADE & Eomjoceno \\
\hline
\end{tabular}

\section{Referências}

Beurlen K.1958. Contribuição à paleontologia do estado do Pará. Crustáceos decápodes da Formação Pirabas I- (Arthropoda- Crustacea). Boletim do Museu Paraense Emílio Goeldi, nova série, Geologia, 5:1- 48.

Bishop G.A.1986. Taphonomy of the north american decapods. $J$. Crustacean Biol., 6:326-355.

Brito I.M.1971. Contribuição ao conhecimento dos crustáceos decápodes da Formação Pirabas I- Brachyura- Brachyrhyncha. Anais Acad. Bras. Ciênc., 43 (suplemento):489- 498.

Brito I.M.1993. O aspecto moderno da carcinofauna da Formação Pirabas, Oligo- Mioceno do estado do Pará. Anais Acad. Bras. Ciênc., 65:57-61.

Brooks H.K., Carpenter F.M., Glaessner M.F., Hahn G., Huffman R.L., Holthuis L.B., Manning R.B., Manton S.M., McCormick L., Moore R.C., Newman W.A., Palmera A.R., Rolfe D.I., Tasch P., Winter T.H., Zullo V.A. 1969. Arthropoda 4. In: R.C. Moore (ed.), Treatise on Invertebrate Paleontology. Lawrence, The Geological Society of America and The University of Kansas, v.2, 651p.

Costa J.B.S., Borges M.S., Bemerguy R.L., Fernandes J.M.G., Costa Jr. P.S., Cpsta M.L. 1993. Evolução Cenozóica da Região de Salinópolis, Nordeste do Estado do Pará. Geociências, 12(2):373396.

Fernandes J.M.G. 1988. Bioestratigrafia da Formação Pirabas, Estado do Pará. In: SBG, Cong. Bras. Geol., 35, Belém, Anais, 6:2376- 2382.

Fernandes J.M.G. \& Távora V.A. 1990. Estudo dos foraminíferos da Formação Pirabas procedentes do furo CB-UFPa-P1(85), município de Capanema, Estado do Pará. In: SBG, Cong. Bras. Geol., 36, Natal, Anciis, 1:470-475.

Ferreira C.S. 1966. Características lito-paleontológicas da Formação Pirabas, Estado do Pará. In: Conf. Geol. Guianas, 6, Belém. Ancis, Avulsos da Divisão de Geologia e Mineralogia, 41:101-111.

Ferreira C.S.1967. Contribuição à Paleontologia do Estado do Pará. O gênero Orthaulax Gabb, 1872 na Formação Pirabas. In: CNPq, Simp. Biota Amaz., 1, Belém. Atas, 1 (Geociências): 169- 181.

Ferreira C.S. 1980. Correlação da Formação Pirabas (Mioceno Inferior), $\mathrm{N}$ e NE do Brasil, com as Formações Chipola e Tampa da península da Flórida, USA. In: APA, Cong. Latinoamer.Paleont., 1, Buenos
Aires, Atas, 3:49-55.

Ferreira C.S. 1982. Notas Estratigráficas Sobre o Cenozóico Marinho do Estado do Pará. In: SBG, Simp. Geol. Amaz., 1, Belém, Anctis, 1:84-88.

Ferreira C.S. \& Cassab R.C.T. 1985. Implicações faciológicas da família Pectinidae (Mollusca-Bivsalvia) da Formação Pirabas, OligoMioceno do norte e nordeste do Brasil. In: Coletânea de Trabalhos Paleontológicos, MME-DNPM, Série Geologia 27, Seção Paleontologia e Estratigrafia 2: 205-209.

Ferreira C.S \& Cunha O.R. 1957. Contribuição à Paleontologia do Estado do Pará. Notas sobre a Formação Pirabas com a descrição de novos invertebrados fósseis. I. (Mollusca- Gastropoda). Bol. Museu Paraense Emílio Goeldi, nova série Geologia, 2:1-61.

Ferreira C.S. \& Francisco B.H.R. 1988. As relações da Formação Pirabas (Oligoceno-Mioceno), com as formações continentais terciárias no NE do Pará. In: SBG, Cong. Bras. Geol., 35, Belém, Ancis, 2: 761 764.

Francisco B.H.R., Loewenstein P., Silva O.F., Silva G.G. 1971. Contribuição à Geologia da Folha de São Luís (SA-23) no Estado do Pará. III- Estratigrafia. IV-Recursos Minerais. Bol. Museu Paraense Emílio Goeldi, nova série Geologia, 17: 1-40.

Fursich F.T. \& Oschmann W. 1993. Shell beds as tools in basin analysis: the Jurassic Kachchh, western India. J. Geol. Soc. London, 150:169-18.5.

Góes A.M., Rossetti D.F., Nogueira A.C.R., Toledo P.M. 1990. Modelo deposicional preliminar da Formação Pirabas no nordeste do Pará Bol. Museu Paraense Emílio Goeldi, série Ciências da Terra, 2:3-15.

Kidwell S.M. \& Holland S.M.1991. Field description of coarse bioclastics fabrics. Palaios, 6:426- 434

Kidwell S.M., Fursich F.T., Aiger T.1986. Conceptual framework for the analysis and classification of fossil concentration. Palcios, 1:228238.

Latreille M.1819. Encyclopédie méthodique. Histoire Naturelle. Entomologie, ou Histoire naturelle des crustacés, des arachnides et des insectes. Paris, 10, 832p.

Maury C.J. 1925. Fósseis terciários do Brasil com descrição de novas Formas Cretáceas. Rio de Janeiro, Serviço Geológico e Mineralógico do Brasil, 665p. (Monografia 4).

Melo G.A.S.1996. Manual de identificą̧ão dos Brachyura (caranguejos e siris) do litoral brasileiro. São Paulo, Editora Plêiade/FAPESP, $603 p$.

Petro S. 1957. Foraminíferos miocênicos da Formação Pirabas. Bol. Fac. Fil. Ciênc. Let., Universidade de São Paulo, 216(16): 1-79.

Rathbun M.J.1918. The grapsoid crabs of America. Smithsonian Institute, United States National Museum Bulletin, 97:1-461.

Rathbun M.J. 1919. Decapod crustaceans from the Panama region. Smithsonian Institute, United States National Museum Bulletin, 103: $123-184$

Rathbun M.J.1924. Fossil crabs from the Republica of Haiti. Smithsonian Institute Proceedings, United States National Museum, $63(9): 1$ 328.

Simões M.G.1996. Pelecypod taphofacies of the Corumbatai formation (Late Permian) in central São Paulo state, Paraná basin. In: SBG, Cong. Bras. Geol., 39, Salvador, Anciis, 2:298- 300.

Távora V.A. \& Fernandes J.M.G. 1999. Estudio de los foraminíferos de la Formación Pirabas (Mioceno Inferior), Estado de Pará, Brasil y su correlación com faunas del Caribe. Revista Geol. America Central, 22:63- 74 .

Vega F.J., Feldmann R.M., Villalobos-Hiriart J.L., Gío-Argíez R.1999. A new decapod fauna from the Miocene Tuxpan formation, eastern Mexico. J. Paleont., 73:407-413.

Manuscrito A-1241

Recebido em 30 de julho de 2001

Revisão dos autores em 30 de junho de 2002 Revisão aceita em 10 de julho de 2002 